\title{
Evaluation of Sustainable forest Management of Iran's Zagros forests
}

\section{MEHDI ZANDEBASIRI ${ }^{1}$, JAVAD SOOSANI ${ }^{2}$, MEHDI POURHASHEMI ${ }^{3}$}

\author{
${ }^{I}$ Department of forestry, Behbahan Khatam Alanbia University of Technology, Iran \\ ${ }^{2}$ Department of forestry, Lorestan University, Iran \\ ${ }^{3}$ Research institute of Forests and Rangelands, Agricultural Research Education and Extension Organization (AREEO), Iran \\ Corresponding author Mehdi Zandebasiri,: Mehdi.zandebasiri@yahoo.com
}

\begin{abstract}
Sustainable Forest Management (SFM) means management of forest resources that consideration the needs of the current generation without risking ability of future generations to attain their needs. Evaluation of SFM needs to design a feedback information system to monitoring of forest resources. In this research, sustainability indicators based on the SMART\&D framework were prepared in Tange-Solak local area in Zagros forest, Iran. Based on this, 7 indicators of ecosystem features were provided for evaluation of SFM. Here, Sustainability Index (SI) was used in evaluating SFM via fuzzy membership function. The results reveal that, Forest SI was eventually obtained as 0.15 . This number $(0.15)$ was obtained from the Fuzzy approach used in this study for an SI value far lower for forest sustainability compared to the number 1 (maximum value). (C) JASEM

https://dx.doi.org/10.4314/jasem.v21i5.3
\end{abstract}

Keywords: Fuzzy logic, Criteria, indicators, Sustainability Index (SI)

Sustainable Forest Management (SFM) means management of forest resources that meet current generation needs without decrease of future generations to meet their needs (Elbakidze, \& Angelstam, 2007). The most common expression of SFM aspects are social, recreational, economic and environmental sustainability. (Wang, 2004). One of the key problems is ability to have common tools in SFM. Since 1992, various Conferences and Sessions have been held to arrive at a unified criteria and indicators for that. Criteria are described and evaluated with a number of indicators related to that. Selected criteria for sustainability helps in determining a decision on what should be sustained. Achieving to a criterion is measured by an indicator. A special indicator is a measurement tool of one dimension of the criteria. The indicators are controlled to evaluate the obtained results. The most analyzed results and problems of SFM in Iran have been compilation and evaluation of criteria and indicators. Evaluation of SFM is considered after gatheing list of criteria and indicators. In SFM evaluation, current values of indicators are compared with a set of reference values. This process guarantees continue of the life in the system. Systems without the feedback process will die. Therefore, evaluation of SFM is necessary to ensure permanent functions of forests (Wolfslehner \& Vacik, 2011).

Zagros vegetation region is located in the West and Southwest of the country of Iran. Nowadays, these forests are in severe quantitative and qualitative danger due to the following: climatic change, livestock overgrazing in the forest, and lack of traditional knowledge about local resident
(Ghazanfai et al, 2004; Zandebasiri \& Ghazanfa, 2010, Pourhasheme et al., 2013). Local resident in these forests have complex and difficult lives in compared to those living in other parts of the country (Imani Rastabi et al, 2015). Traditional usings to meet the needs of local residents are common in almost all of the Zagros forests, despite prohibits of the executive management (Ghazanfari et al., 2004). These forests have important functions in water, soil, socio-economic and paly an significant role in ecological balance of the region.

SFM has a specified importance due to existence of these problems in forests (Zandebasiri \& Parvin, 2012). These forests play a vital role in water, soil and ecological balance management of the region (Ebrahimi Rostaghi, 2006). In the past decades, forests of this vegetation region have experienced severe intervention of humans and their dependence (Valipour et al., 2014). Development of agricultural lands, fuel supply, public poverty among forest dwellers, youth unemployment among forest dwellers and the lack of appropriate socio-economic development is threatening the stability of Zagros forests (Zandebasiri \& Ghazanfari, 2010). In the field of SFM in Iran's Zagros forest, Zandebasiri \& Parvin (2012) studied the importance of criteria and indicators of Near East process in sustainable management of tangeSolak forests in Kohgilouyeh and Boyerahmad State. The research method was Likert scale. The results revealed that criteria of forest resources as well as the protective role and legal-institutional 
framework are the main criteria of Near East process for the studied region.

\section{MATERIAL AND METHODS:}

Study area: The examined local area is the catchment of Tange-solak in the province of Kohgilouye and Boyerahmad. Tange-solak forest is located in Likak city, which is approximately $15 \mathrm{~km}$ south of Kohgiloye and Boyer Ahmad province. This forest has an area of 1000 hectares. There are also agricultural and horticultural lands in this region. The main agricultural products include wheat and barley. Also, natural cypress trees form unique stand of cypress-oak. The existing forest has a high scientific value and it can be called living fossil. Most people residing here have relocated from the region due to lack of facilities and low income. While the rest of them left behind do not have permanent residence in the forest; these migrate to tropical regions in the period of October to late winter. In the current situation, forest preservation plan is applied for the region with a focus on forest resources protection by the executive management. The people still living here get drinking water from a spring which is in Tange-solak itself. Effect of dieback and decline has started in the region in previous years.

\section{Methodology:}

In classical or Aristotelian logic, the correct phrase is presented with number (1) while incorrect phrase is shown with number (0). This implies that logical propositions have two values. Classic collections are also referred to as "definitive collections". If an element or a number such as $X$ and a collection such as $A$ exist, then there are two resulting modes based on the classic logic:

If $X$ is a member of $A$ then it is written as $x \in A$, and if $X$ is not a member of $A$ then it is written as $x \notin A$. This is revealed by an indicator function $\mu_{A}(x)$ as shown below:

$f(x)= \begin{cases}1, & x \in A \\ 0, & x \notin A\end{cases}$

This means that if one member is present in set of $A$ it has membership size of (1) implying that $\mu_{A}(x)=1$ and if one member is not present in set of $A$ it has membership size of (0), implying that $\mu_{A}(x)=0$ thus membership in a classic set is defined as definitive and accurate. This also means that an object or an element is either a member of a set or not. The membership function can only have two sizes of zero and one, implying that propositions have two values. Polish Lukasiewicz attempted to solve the above problem by compiling "3 valued logic" through addition of one state to 2 valued logic. In 3 valued logic, the correct value is shown by (1), incorrect value is shown by (0) and neutral or uncertain value is shown by (2.1). Three (3) valued logic has no contradiction with 2 valued logic; it only expended it. The membership function for 3 valued propositions are as follows:

$\mu_{A}(x)=\left\langle 0, \frac{1}{2}, 1\right\rangle$

In fuzzy logic, according to Professor Zadeh's theory (Zadeh, L.A), unlike 2 and 3 valued logics, the indicator or membership function of $\mu_{A}{ }^{(x)}$ for a fuzzy set is such that $\mu_{A}(x)$ shows a grade or rank that each $X$ element available in $A$ set with that grade is related to a fuzzy set of A. In this way, all the elements can be related to one set with different membership grades from zero to one (Zandebasiri et al., 2012).

The objective of this paper is the compare of current values of indicators with a set of threshold values with using fuzzy logic. This can determine sustainability index for the local area in Zagros forests.

The research process has been conducted in three sections. In the first section of the research, sustainability indicators based on the SMART\&D framework were prepared by analysts to evaluate SFM. Based on the SMART\&D framework, a performance evaluation indicator in a system should have the following characteristics (Davis et al., 2001): being Specific (S), being Measurable (M), being Achievable (A), being Realistic (R), being Time framed $(\mathrm{T})$ and being Database (D). Based of SMART \& D, 8 indicators of ecosystem features were provided for SFM evaluation. In the second section of the research, by expert's opinions, paired comparisons were used to determine the importance of indicators discussed. In the third section of the research, Sustainability Index (SI) were used to SFM evaluation. SI obtained from the following equation was used for evaluation of SFM (Mendoza \& Prbhu, 2003):

$$
S I=\sum \mu_{\mathrm{x}} w_{x}
$$


In Equation 1, SI is sustainability index for a forest; here $\mu_{\mathrm{x}}$ is a fuzzy membership value which is calculated by the following equation:

$$
\mu_{x}=\left\{\begin{array}{cc}
0 & x \leq a_{1} \\
1-\frac{\beta-x}{\beta-\alpha} & \alpha \leq x \leq \beta \\
1 & x \succ \beta
\end{array}\right\}
$$

In Equation 2, $\mu_{x}$ is a fuzzy membership value of indicators in sustainability sign, $x$ is the average value of an indicator obtained from an average of all calculated numbers of intended indicator in the forest. $\alpha$ and $\beta$ are obtained from the estimation of professional experts for lower and upper limits of the intended indicator. $\alpha$ parameter simply means a limit where if one certain indicator is lower than that amount then the forest becomes unsustainable. Hence, $\alpha$ refers to the minimum reference value. $\beta$ parameter implies that if the value of a certain indicator is larger than $\beta$ then the forest is completely sustainable. In other words, $\beta$ is the maximum reference value.

In this research, 12 one-hectare plots were randomly implemented to determine the current values of indicators as well as the numbers related to $\mathrm{X}$ for Equation (2). Reference values were also determined using opinions of three professional experts.

In Equation (2), $\mu_{\mathrm{x}}$ is in effect a fuzzy membership function for interpretation of a fuzzy indicator.

Table 1: Outcomes of paired comparison of

\begin{tabular}{lc}
\multicolumn{1}{c}{ indicators' weight } \\
\hline \multicolumn{1}{c}{ Name of indicator } & Weight of indicators \\
\hline The number of stages & 0.13 \\
Density of number per hectare & 0.10 \\
The numbers of trees per hectare with a healthy & 0.14 \\
crown & \\
Average height of pile & 0.10 \\
Litter depth in millimeters & 0.11 \\
Canopy cover percentage & 0.10 \\
Average number of species in each plot & 0.14 \\
Regeneration level in hectare per square meter & 0.18 \\
\hline
\end{tabular}

The result of the third section of the research, are as shown in Table $2 \&$ Table $3 \&$ Table $4 \&$ Table 5. Results of sampling from forest in terms of average value for indicators is as shown in Table 2. Observed results from an examination of the minimum and maximum threshold values is as shown in Table 3. $\mu_{x}$ is fuzzy membership value as shown in Table 4. Normalized $\mu_{\mathrm{x}}$ values are as shown in Table 5 .
Fuzzy membership values for indicators are normalized to achieve a better interpretation of $\mu_{x}$ number. Normalization has to do with generating numbers without scale. Satty Norm was used in this research to generate numbers without scale. In Satty Norm $\frac{b}{b_{\max }}$ formula is used in which $\mathrm{b}$ is a certain number in table of numbers and $b_{\max }$ is the biggest number of this table.

In Equation (1) and in order to calculate SI, it is required that the weight of each of the indicators be determined. In Equation (1) $\mathrm{w}_{\mathrm{x}}$ is the weight of $\mathrm{x}$ indicator. $\mathrm{w}_{\mathrm{x}}$ expresses the relative importance of each indicator compared to other indicators. Also, paired comparisons were used to determine the importance of indicators discussed.

\section{RESULTS AND DISCUSSION}

The result of the first section of the research showed the number of stages, density of number per hectare, numbers of trees per hectare with a healthy crown average height of pile, litter depth in millimeters, canopy cover percentage, average number of species in each plot, as well as regeneration level in hectare per square meter were identified as capable indicators of SMART\&D.

The result of the first section of the research, the outcomes of paired comparison of investigated indicators' weight are as shown in Table 1:

Table 2: Results of average value for indicators of sampling from forest

\begin{tabular}{lc}
\hline Name of indicator & $\begin{array}{c}\text { Average value for } \\
\text { indicators }\end{array}$ \\
\hline The number of stages & 1 \\
Density of number per hectare & 181 \\
The numbers of trees per hectare with a healthy crown & 164 \\
Average height of pile & $4 / 3$ \\
Litter depth in millimeters & $1 / 8$ \\
Canopy cover percentage & 40 \\
Average number of species in each plot & $1 / 5$ \\
Regeneration level in hectare per square meter & 0 \\
\hline
\end{tabular}

Table 3: Result of examining the minimum and maximum threshold values

\begin{tabular}{lcc}
\hline Name of indicator & $\boldsymbol{\alpha}$ & $\boldsymbol{\beta}$ \\
\hline The number of stages & 1 & 3 \\
Density of number per hectare & 150 & 280 \\
The numbers of trees per hectare with a healthy crown & 163 & 179 \\
Average height of pile & 3 & 10 \\
Litter depth in millimeters & 1 & 10 \\
Canopy cover percentage & 25 & 75 \\
Average number of species in each plot & 1 & 3 \\
Regeneration level in hectare per square meter & 0 & 3000 \\
\hline
\end{tabular}


Table 4: Fuzzy membership value of indicators

\begin{tabular}{lc}
\hline Name of indicator & $\boldsymbol{\mu}_{\mathbf{x}}$ \\
\hline The number of stages & 0 \\
Density of number per hectare & $0 / 24$ \\
The numbers of trees per hectare with a healthy crown & $0 / 06$ \\
Average height of pile & $0 / 19$ \\
Litter depth in millimeters & $0 / 09$ \\
Canopy cover percentage & $0 / 30$ \\
Average number of species in each plot & $0 / 25$ \\
Regeneration level in hectare per square meter & 0 \\
\hline
\end{tabular}

Due to the breadth of evaluation indicators of SFM, indicators related to the management measures, socio-economic and organizational characteristics are expected to be studied in other examinations. In the next step, paired comparisons were conducted for these indicators. From the result of paired comparisons (Table 1), regeneration was expected to have high weight (importance of 0.18 ). Regeneration is the future of forests and guarantees the replacement of old trees and forests (Pourhashemi et al., 2013). The level of regeneration had the most importance in paired comparisons compared to the indicators examined; however, based on the fact that there is no regeneration in the region, it will have $\mu_{x}$ of zero. Also, the weight of number density indicator per hectare was expected to be low due to the fact that density in Zagros forests includes all bases of coppice and single trunk. Single trunk trees such as seed origin and branch origin is vague. Due to different functions of seed and branch origin, trees are not explicitly identified in Zagros forests; also, the indicator of density per unit area cannot have a high value among other indicators. Most astonishing of all is the low percentage of canopy cover importance (0.10). It was expected that the indicator of canopy cover percentage appears highly important due to the protective function of Zagros forests, however, due to the onset of dieback in the middle of Zagros forests and direct relation between decline and larger crowns (Hoseinzadeh \& Pourhashemi, 2015), it seems that the health of the crown should be necessarily considered in SFM evaluation along with canopy cover percentage. Results of sampling from the forest (Table 2) indicates the terms of an ecosystem that has been destroyed. Forests have one stage in all plots. This is due to destruction of the vertical structure of forest and equality of approximate tree heights, a factor which leads to reduced mass resistance against climate adversities. The findings of this table reveal that about $10 \%$ of
Table 5: The results of normalized $\mu_{\mathrm{x}}$ of indicators

\begin{tabular}{lc}
\hline Name of indicator & Normalized $\boldsymbol{\mu}_{\mathbf{x}}$ \\
\hline The number of stages & 0 \\
Density of number per hectare & $0 / 21$ \\
The numbers of trees per hectare with a healthy & $0 / 05$ \\
crown & \\
Average height of pile & $0 / 17$ \\
Litter depth in millimeters & $0 / 08$ \\
Canopy cover percentage & $0 / 27$ \\
Average number of species in each plot & $0 / 22$ \\
Regeneration level in hectare per square meter & 0 \\
\hline & \\
Ultimately, Forest SI was obtained & 0.15 using \\
$S I=\sum w_{x} \mu_{\mathrm{x}}$ formula.
\end{tabular}

trees do not have healthy crown. The average height of the mass is very low ( $4.3 \mathrm{~m}$ on average) along with measured leaf litter size which were smaller than 2 $\mathrm{mm}$ (on average). Habitat weakness due to history of socio-economic problems, rock protrusions and soil erosion are reasons for this matter. Only one main species (Quercus brantii) was observed in most plots. And only a few plots had natural cypress, Acer cineracens and hawthorn were together such that the average number recorded in species diversity for 12 plots was 1.5. Table 3 presents an estimated value of the threshold using the expert opinions. The purpose of numbers $\alpha$ and $\beta$ for each indicator is the minimum and maximum thresholds of sustainability. For example, in terms of canopy cover percentage, forest life will be threatened if the size of $\alpha$ is less than $25 \%$, and if it exceeds $75 \%$, the forest is completely sustainable in terms of canopy cover percentage. The value of fuzzy membership indicators is provided in Table 4. This indicator is actually an average value based on a combination of current values (sampling results) as well as minimum and maximum values with normalized numbers as shown in Table 5 . Normalization method involves comparing numbers to define all numbers in scale one (collectively they are one). A cross-section of $\mu_{\mathrm{x}}$ values in Table 5 among studied indicators revealed that the lowest values of $\mu_{\mathrm{x}}$ were related to the natural regeneration level and the number of stages. The lack of natural regeneration is an observable problem in most regions of Zagros forests (Pourhashemi et al., 2012). Various reasons such as socio-economic problems and soil compaction due to repeated movement of livestock, rock protrusions in many regions and soil erosion can be expressed as the most important reason for this issue (Zandebasiri \& Parvin, 2012). No natural regeneration level has been recorded in the study area. It appears that with increasing age of oak trees, forest regeneration crisis is a topic that currently threatens the survival and future of forests. 
All reported $\mu_{\mathrm{x}}$ numbers report a very low and unstable condition; however, density and canopy cover indicators display better condition among them, hence it is necessary in this context to express that these 2 indicators are minimum requirements for the aristocratic existence of forests. $\mu_{\mathrm{x}}$ is extremely low for other indicators such as average height, depth of leaf litter and species diversity with all indicating the severity of destruction in Zagros forest ecosystems. Thus, the crisis of oak decline in these forests can be said to also be in the preliminary phase. The $\mu_{\mathrm{x}}$ value for the number of trees with healthy crown is also extremely low (0.05) which can indicate the commencement of defoliation and forest decline in crown of Iranian oak trees in the region. SFM evaluation can help in defining a preliminary warning for forest management. Research findings reveal that the prevailing condition in the region's forests is a dangerous type and various disastrous situations have been prepared for the forest system. Obviously, if the main problem of these forests in the field of indicators such as socio-economic encroachment to the fields of forest (Ebrahimi Rostaghi, 2006), improvements in the livelihood of the local community along with their participation in forest management (Imani Rastabi et al., 2015) are not resolved, in the future, various crises of soil, forest regeneration and severe deterioration, as well as performance of various functions of the forest will reach their lowest level, an issue that will deprive future generations of the Forest Service.

Conclusion: $\mu_{\mathrm{x}}$ fuzzy calculation method along with the ultimate ability to combine it with weight indicators results in extraction of a number between zero and one and rather than comparing between completely stable and completely unstable form, a fuzzy approach is created for evaluation of sustainability and determination of the sustainability limits in range of zero and one. The number 0.15 is a number obtained from fuzzy approach and used in this study for an SI value, that is, a very low number for forest sustainability compared to the number 1 (maximum value).

\section{REFERENCES}

Davis, L.S.; Johnson, K.N.; Bettinger, P.S.; Howard, T.E., (2001). Forest Management: To Sustain Ecological, Economic, and Social Values, 4th ed.; McGraw-Hill Publication.

Ebrahimi Rostaghi, M., (2006), The role of policy-making and decision-making in protection of outside North forest's, Conference on protection of forests in sustainable forest management, Forestry Community of Iran, p: 137-151 (In Persian).
Elbakidze, M. \& P. Angelstam, (2007). Implementing sustainable forest management in Ukraine's Carpathian mountain: The role of traditional village systems, Forest ecology and management: 249: 28-38.

Ghazanfari H., Namiranian M., Sobhani H., Mohajer R.M., (2004). Traditional forest management and its application to encourage public participation for sustainable forest management in the northern Zagros mountain of Kurdistan province, Iran. Journal of Scandinavian Journal of forest research, 19: 65-71.

Hoseinzadeh, J. \& M. Pourhashemi, (2015). The study of crown indicators in Quercus brantii tress in relationship with mortality phenomenon in Ilam forest's, Iranian journal of forest, 7(1): 57-66 (In Persian with English abstract).

Imani Rastabi, M., H. Jalilvand and M. Zandebasiri, (2015). Assessment of socio-economic criteria and indicators in monitoring of Kalgachi lordegan forest management plan, Iranian Journal of Forest and Poplar Research, 23 (2): 1-8 (In Persian with English abstract).

Mendoza, G. A. \& R., Prbhu, (2003). Fuzzy methods for assessing criteria and indicators of sustainable forest management, Eclogical indicators, 3: 227-236.

Pourhashemi, M., Panahi, P., Zandebasiri, M. (2012). Estimation of acorn production of gall oak (Quercus infectoria Olivier) in Baneh forests using Koenig visual method. Iranian J. Forest Poplar Res. 19 (2), 194-205 (in Persian with Englisg abstract).

Pourhashemi, M., Panahi, P., Zandebasiri, M. (2013). Application of visual surveys to estimate acorn production of Brant's oak (Quercus brantii Lindl.) in northern Zagros Forests of Iran. Caspian Journal Environ. Science, 11: 85-95.

Valipour, A., T., Plieninger, Z., Shakeri, H., Ghazanfari, M., Namiranian, M. J. Lexer, (2014). Traditional silvopastoral management and its effects on forest stand structure in northern Zagros, Iran, Forest ecology and management, 327 : 221-230.

Wang, S., (2004).One hundred faces of sustainable forest management, Forest Policy and Economics, 6: 205-213.

Wolfslehner, B. and Vacick, H., (2011). Mapping indicator models: from intuitive problem structuring to quantified decision-making in sustainable forest management, Ecological indicators, 11: 274-283.

Zandebasiri, M., \& H. Ghazanfari, 2010.The main consequences of affecting factors on forest management of local settlers in the Zagross forests (case study: Ghalegol watershed in Lorestan province), Iranian Journal of Forest, 2(2), 127-138.

Zandebasiri, M. \& T., parvin, 2012. Investigation on importance of Near-East process,s criteria and indicators on sustainable management of Zagros forests (Case study: Tange-Solak watershed of Kohgilouye and Boyerahmad province), Iranian Journal of Forest and Poplar Research, 20(2): 204-216.

Zandebasiri, M., H., Ghazanfari, R., Abbasi and E., Sayad, 2012. The use of fuzzy pairwise comparisons to determine most important factors of forest management plans in Iran, Scholarly journal of agricultural science 2(9): 271-223. 